\title{
El "Primer Catolicismo Social" ante la cuestión social: un momento en el proceso de consolidación nacional
}

\section{LOS PRIMEROS MOMENTOS REPUBLICANOS}

La república de Chile, como la mayoría de los Estados surgidos del desmembramiento del imperio español, se constituyó más como alternativa única a la monarquía que como una decisión política de su pueblo. Aunque se reconociera que el republicanismo era el régimen ideal al cual el progreso debía conducir como resultado de su proceso civilizador, la república, en un primer momento, correspondiente al de sus primeras constituciones hasta la de 1833, fue entendida como una forma de gobierno representativo conducente al bien común, el cual aportaba el marco jurídico-cultural para que las virtudes cívicas afloraran y se desarrollaran. Sin embargo, aunque el pueblo era el depositario teórico de la soberanía, solo podría asumir en el tiempo los derechos de esta, es decir, cuando la virtud y la civilización hubieren traspasado hacia los sectores más bajos de la población. Desde esta visión, representativa de la clase dirigente durante una gran parte del siglo XIX, el Estado iría configurando una nación donde eran aceptadas las exclusiones tanto civiles como políticas mientras el proyecto civilizador tomaba forma (1). Por lo tanto, sería desde la república desde donde debía surgir una comunidad nacional congruente con ella en un proceso de construcción cultural más que de apelación a una comunidad histórica preexistente, o a principios de legitimidad históricamente válidos, como habían sido la trascendencia o la figura del rey durante el Antiguo Régimen. Se trataba de lo que Anthony Marx llama una "cohesión exclusionaria" donde la ciudadanía era asignada selectivamente y no en forma universal (2). Sin embargo, en este escenario, la unión entre Estado e Iglesia y la asociación constitucional de la patria con la religión católica eran pilares sobre los cuales se apoyaba la posibilidad de transitar de la legitimidad antigua a la nueva; de la legitimidad monárquica a la republicana. Desde la década de 1840 se escucharon voces que buscaban incorporar

(1) A. M. Stuven, La seducción de un orden - Las elites y la construcción de Chile en las polémicas culturales y políticas del siglo XIX, Ed. Universidad Católica, Santiago 2000.

(2) A. Marx, Faith in Nation. The exclusionary origins of Nationalism, Oxford University Press, New York 2003. 
nuevos sectores a la discusión política e integrarlos a los derechos de la soberanía nacional que la república proclamaba como su principio guía. Hombres como Francisco Bilbao, Santiago Arcos, por nombrar los más "radicales", habían planteado la necesidad de incorporar a los artesanos y obreros a los bienes de la nueva polis, denunciando que las exclusiones a los derechos que permitía la constitución atentaban contra la definición republicana del Estado y contra el principio de soberanía nacional que suponía una nación inclusiva de todos los habitantes. Se impuso, por tanto, la necesidad de pensar la representación nacional, y vincular la ciudadanía con la nación; de pensar en derechos. Este constituye a nuestro juicio un segundo momento en el proceso de formación de la nación chilena moderna, cuando se incorpora como actores sociales e integrantes de la república a sectores del pueblo con una identidad reconocible. Ello significa que el concepto de pueblo comienza a corporizarse en sectores concretos de la población: los artesanos, por ejemplo. Aunque representadas discursivamente por miembros de la clase dirigente, sus demandas adquieren legitimidad a través de la formación de asociaciones para canalizar sus intereses, o a través del apoyo a movilizaciones que les hagan aparecer públicamente. Es el caso de la Sociedad de la Igualdad, por ejemplo, reprimida y clausurada en 1851.

Estas tensiones provocaron nuevas polaridades, en primer lugar, aquella ideológica entre autoritarismo y liberalismo por las influencias del pensamiento republicano francés y por el surgimiento de una sociedad capitalista de corte liberal. Este nuevo conflicto obligó a reformular el discurso republicano para dar forma a una comunidad política estable donde sus integrantes pudieran vivir juntos con justicia y libertad bajo la protección de la ley, y donde fueran reemplazadas las formas de legitimación tradicionales, como la religión, por formas congruentes con los "derechos del hombre y del ciudadano". Ello conllevaba la ampliación de las bases sociales de la república.

En este segundo momento surge, aunque excepcional y embrionariamente, una definición de la nación que enfatiza la soberanía del pueblo y la necesidad de educarlo para transitar hacia la república democrática. Es lo que algunos autores han identificado como el tránsito del "momento maquiavélico" al "momento lockeano", o del énfasis en las prerrogativas del Estado a la defensa de los derechos humanos y naturales (3). La nación republicana aparece como fruto de un orden laico de inspiración liberal que exige adecuaciones en las bases jurídicas del Estado, especialmente en el discernimiento de las esferas pública y privada. Este nuevo escenario suponía una reubicación de la Iglesia Católica en las estructuras de poder, alejándola de las instituciones de poder económico, intelectual o político, y su reemplazo por instituciones estatales que asumieran las funciones sociales de integración de la vida individual a la sociedad. El Código Civil, la supresión de los fueros, las llamadas "leyes laicas", el conflicto educacional y la imposición del Estado docente, son todos aspectos de la construcción de ese orden laico que requiere de nuevas instituciones, que separen el ámbito político del religioso.

(3) T. H. Breen, The Lockean Moment: The language of rights on the eve of the American Revolution, Oxford 2001. 
La lucha por la laicización de las instituciones se situó en este contexto y no implicó de ningún modo un rechazo a la religión católica ni menos una intención de secularización social. Por el contrario, la mayoría de los liberales continuó siendo católico o ejerciendo como tal. Para la preservación del orden social era funcional una Iglesia que en nombre de Dios impusiese el respeto a la ley, que hiciese exigencias de moralidad equivalentes a la virtud cívica, y que reforzase la adhesión al orden público de la clase dirigente.

\section{LA CUESTIÓN SOCIAL}

La llamada "cuestión social" (4) fue un fenómeno que irrumpió en el escenario vital de las clases dirigentes chilenas desde aproximadamente finales de la década de 1870. La migración campo-ciudad y las condiciones de trabajo en la industria y la minería, producto del proceso de incorporación de Chile en la "era del capital", hicieron visible un proletariado cuyas aspiraciones, necesidades y motivaciones lo distanciaban crecientemente del proyecto oligárquico. La clase dirigente, desde la instauración de la república, privilegió la consolidación de su proyecto estatal apoyado en las exclusiones de la participación ciudadana de aquellos grupos que no se incorporaran, vía la educación y la asimilación de sus valores, a su visión del mundo. En 1874 se hicieron importantes reformas legales, especialmente por la sanción del derecho de asociación sin autorización previa, y la ampliación del sufragio, al eliminar la exigencia del "censo". Ello abrió camino para que sectores sociales no oligárquicos pudieran socializar sus demandas tanto hacia la sociedad civil como hacia la sociedad política (5). Esta "valorización del sujeto popular" fue un avance democratizador del sistema político e inclusivo de la nación. No obstante, ello se logró en un contexto de desconfianza y de indecisión respecto de las formas de enfrentar la inclusión.

Este momento representa una mutación en el discurso y en las prácticas, porque, en parte influidos por el mencionado derecho de asociación, se abren derroteros

(4) Hay varias definiciones para el concepto de "cuestión social". James Morris (Las elites, los intelectuales y el consenso. Estudio de la cuestión social y del sistema de relaciones industriales de Chile, Ed. del Pacífico, Santiago 1967) habla de "consecuencias sociales, laborales e ideológicas de la industrialización y urbanización nacientes". Estas tendrían relación con la vivienda, la salud, los derechos de los trabajadores, las huelgas y la proliferación de ideas extremistas. Sergio Grez Toso (La "cuestión social" en Chile. Ideas y debates precursores (1804-1902), DIBAMCentro de Investigaciones Diego Barros Arana, Santiago 1997) cita la definición de Morris. Mario Garcés incluye como temática de la cuestión social no solamente las consecuencias sino las condiciones mismas de vida que afectaban a los sectores populares (1900); Gonzalo Vial, Historia de Chile (1891-1973), Vol. I, tomo II, Ed. Santillana, Santiago 1981, considera que fue "el hecho histórico más importante en nuestro cambio de siglo", cuando "las clases trabajadoras se vieron sometidas a una presión aplastante" por problemas económicos, sanitarios, de salud y morales que les fueron haciendo insoportable la existencia (p. 496).

(5) Aunque la participación electoral en este período nunca sobrepasó el $10 \%$ de la población total, en parte porque se mantuvo el requisito de saber leer y escribir, siendo que solo en la década de 1920 el porcentaje de alfabetos sobrepasaría la mitad de la población adulta. Ver J. S. Valenzuela, "Hacia la formación de instituciones democráticas: Prácticas electorales en Chile durante el siglo XIX”, Estudios Públicos, 66, otoño 1997. 
para que sectores de trabajadores reformulen sus relaciones con el Estado. Como sostiene Hilda Sábato citando a F.X. Guerra, surgieron formas de sociabilidad nuevas que "extraían su legitimidad no de la costumbre o de la ley, sino de la asociación misma, de la voluntad de los asociados, entendidos como individuos libres e iguales entre sî́. En esta nueva etapa, el republicanismo fue redefinido para incluir a los frágiles sectores medios y populares (6). El control férreo del aparato del Estado a manos de la oligarquía impedía que las disensiones internas o la ampliación de los derechos políticos traspasaran los límites que su cohesión social garantizaba, amenazando su poder social. Sin embargo, el surgimiento de un sector social con una cierta autonomía cultural respecto de la clase dirigente obligaba a esta a pensar la política no solamente con relación al Estado sino también hacia lo social; implicaba plantearse problemas, como la relación entre capital y trabajo y los derechos civiles de los trabajadores, es decir, obligaba a pensar a otros grupos sociales hasta ese momento al margen de la discusión pública. Parafraseando a Luis Alberto Romero, el nuevo contexto socioeconómico y cultural, llamado la "cuestión social" hizo más patente la pregunta que algunos habían comenzado a plantearse algunas décadas antes: ¿Qué hacer con los pobres? (7)

Indudablemente la pregunta surgió porque se hacía necesario enfrentar la situación; los sectores populares debían ocupar algún lugar en la estructura de un Estado que se concebía a sí mismo en forma y, en consecuencia, debían ser integrados a la nación que este cobijaba. La pregunta interpeló a todos aquellos que ocupaban posiciones de liderazgo en el país. La primera reacción de una oligarquía que se encerraba cada vez más en torno a sí misma fue negar el problema. En la década de 1880, se comenzó a admitir la proximidad de un conflicto social por las reivindicaciones populares y el avance de las ideas socialistas, y mientras el Partido Demócrata denunciaba a la oligarquía como enemiga de la democracia y del principio de soberanía nacional, se agravaban los problemas de vivienda, higiene, salud y miseria que afectaban a los más pobres. No obstante, ni el liberalismo ni el radicalismo tuvieron reacciones tempranas ni formularon propuestas concretas ante el flagelo social que se hacía visible.

El Partido Conservador, representante del mundo católico, se vio enfrentado tempranamente a este proceso. Hasta 1870 , los principales enemigos del catolicismo chileno habían sido el liberalismo secularizador y el protestantismo. Por cierto, el miedo católico tenía ya su historia, desde que el primer arzobispo de Santiago, Rafael Valentín Valdivieso fundara la Revista Católica en 1842 para combatir sus efectos sobre las conciencias. Ejemplarmente, la Iglesia usaba los recursos de la modernidad para combatir contra ella. Su compleja manera de insertarse en los nuevos tiempos incluyó siempre el diálogo republicano al interior del sistema político a través del Partido Conservador, cuyos miembros se involucraron en actividades sociales de beneficencia y pudieron así desarrollar cierta sensibilidad social, al mismo tiempo que criticaban el liberalismo y el socialismo. Sin embargo, las cosas

(6) H. Sábato (Coord.), Ciudadanía Política y Formación de las Naciones: Perspectivas históricas de América Latina, Fondo de Cultura Económica, México 1999, 25.

(7) L. A. Romero, ¿Qué hacer con los pobres? Elite y sectores populares en Santiago de Chile, 1840-1895, Ed. Sudamericana, Buenos Aires 1997. 
fueron complicándose cuando los sectores populares tomaron iniciativas que no incluían a la clase dirigente ni a sus representantes, o que estaban abiertamente contra sus intereses. Por ejemplo, cuando surgieron las primeras mutuales, y estas reconocieron a Fermín Vivaceta (1829-1890) como su fundador, su espíritu laico y liberal inquietó a la jerarquía de la Iglesia y a los conservadores, quienes reaccionaron, adecuándose a los signos de los tiempos y estableciendo sus propias asociaciones. La Asociación Católica de Obreros de 1878 y la Unión Católica de 1883, presidida por el conservador Abdón Cifuentes, mantuvieron círculos para trabajadores en barrios populares, siguiendo el ejemplo francés del Conde de Mun y alemán de Adolfo Kolping. Cifuentes fue un pionero en la idea que los católicos no debían abandonar el frente popular al "enemigo", aunque sus principales esfuerzos estuvieran dirigidos a "moralizar" al pueblo. Con esa actitud en cierta forma replicaba la postura conservadora tradicional que consideraba al pueblo como carente de las condiciones mínimas de civilización, pero al mismo tiempo desarrollaba opciones concretas desde el asociacionismo para el mundo del trabajo, demostrando así un reconocimiento al trabajo como un campo de debate republicano (8).

La discusión sobre el trabajo apelaba directamente al desarrollo capitalista y sus dilemas. El proteccionismo económico, el mercado y la distribución del ingreso se convirtieron en tema que inspiró voces disidentes dentro del conservadurismo respecto del rechazo obcecado al liberalismo. Zorobabel Rodríguez fue un activo portavoz del liberalismo económico, separándose temprano de las posturas de su partido por su defensa de las llamadas "leyes laicas". En 1876, y como crítica a limitaciones establecidas en el nuevo Código Penal, asumió desde las páginas de $E l$ Independiente el análisis de lo que llamó la "cuestión obrera" estableciendo que la defensa de la "libertad, derecho y garantías" resumían la causa de la justicia. Ante ello, el Estado debía defender el "progreso de la comunidad" a través del ejercicio de sus facultades propias que eran conceder a todos los ciudadanos los mismos derechos sin favorecer a unos ante otros y sin limitar la actividad empresarial con trabas de ningún tipo (9).

\section{EL CATOLICISMO SOCIAL}

El debate sobre el rol del Estado ante el trabajo en un país mayoritariamente católico que se reconciliaba con aspectos del individualismo liberal no podía sino estar íntimamente relacionado con una lectura del mensaje evangélico a la luz de los problemas sociales y políticos que aquejaban al país. En ese sentido, las reacciones del Magisterio no siempre parecían responder a la urgencia que algunos

(8) Sobre el asociacionismo católico, ver G. Vial, op. cit.; P. Valdivieso, Dignidad humana y justicia: la historia de Chile, la política social y el cristianismo, 1880-1925, Ediciones Universidad Católica, Santiago 2006; M. A. Huerta, Catolicismo Social en Chile, Ed. Paulinas, Santiago 1991; R. Krebs et al., Catolicismo y laicismo, Alfabeta, Santiago 1981; F. Silva, "Notas sobre el pensamiento social católico a fines del sliglo XIX", Historia, 4 (1965) 237-262.

(9) Z. Rodríguez, "La Cuestión Obrera, I", El Independiente, 13 de diciembre de 1876, reproducido por S. Grez, op. cit., p. 255. 
católicos percibían ni tampoco tomar la iniciativa de pedagogía social que exigían los católicos. En un contexto político donde urgían definiciones sobre el tránsito de la república oligárquica a la democrática se imponía pensar en ese otro tránsito de la nación excluyente a la nación inclusiva. En resumen, del tránsito hacia una nación de ciudadanos. En este periodo subyace a la discusión sobre los temas sociales y particularmente de la relación entre capitalistas y trabajadores un problema que decía relación con la inclusión de todos los habitantes de la república en el imaginario nacional de la clase dirigente, y su acceso a la ciudadanía activa, entendida como de individuos con derechos reconocidos, reglados por la constitución y las leyes, y basada en la vigencia de ciertos principios sociales y políticos. Estos estipulan que la ciudadanía debe garantizar no solamente los derechos civiles y políticos, sino también los sociales y económicos, como la educación, el trabajo, el bienestar social y la salud. Y, ese tránsito, indudablemente interpelaba al mundo católico.

En el nuevo contexto de proliferación de posturas antisistémicas como el anarquismo, de la evidencia de un movimiento obrero con creciente autoconciencia de sus intereses y demandas, de la penetración del socialismo y su intención de asumir la representación del proletariado, el catolicismo reaccionó oscilando desde dos motivaciones. Por un lado, la de quienes entendían el compromiso social como un deber cristiano de facilitar la incorporación de todos los sectores de trabajadores a la dignidad de ciudadanos de pleno derecho, motivados por el reconocimiento de la situación de miseria y desprotección de los trabajadores. Ellos, influidos por el conocimiento de los problemas sociales europeos y el pensamiento que surgía en torno a ellos consideraron su obligación el mejoramiento de las condiciones sociales y formularon un discurso donde prevalecían los conceptos de derechos sociales y políticos. Según este grupo, la responsabilidad por su resguardo correspondería a todos los actores sociales, incluyendo el Estado. Ellos abogaban por la educación del pueblo, pues asignaban parte de la responsabilidad a la falta de moralidad del mismo, pero también se abrieron a comprender el atractivo del liberalismo y del socialismo y, por lo tanto, a competirles en el terreno de sus reivindicaciones de libertad y participación. También buscaron la mejora en las condiciones de trabajo, el acceso a viviendas dignas, beneficios de salud y previsión y el establecimiento de asociaciones de socorros mutuos como deber de una sociedad cristiana. Por otra parte, estaban aquellos católicos que también veían la urgencia de intervenir ante la cuestión social, pero su motivación surgía más bien como reacción a las presiones obreras y el temor hacia el socialismo y el comunismo. Consideraban que correspondía a los católicos reforzar su compromiso moralizante del pueblo pero no necesariamente involucrarse en propuestas políticas. Opinaban que la superación de la pobreza no era un deber cívico de justicia que involucrara a los católicos, sino más bien un compromiso correspondiente al ámbito de la caridad cristiana. Aunque ninguna de las dos posturas se dio en forma pura, o más bien coexistían en todos los miembros, el problema complicó la relación al interior del Partido Conservador, y entre este y la Iglesia. La primera posición, que nos ocupa aquí, redundó en propuestas que muchas veces no contaron con el apoyo de la jerarquía eclesiástica local y dio origen al catolicismo social; la segunda fue más bien reaccionaria, antiliberal, contraria a la secularización social, temerosa de los nuevos tiempos y unida en torno 
a la defensa contra ellos (10). Para ambas, la promulgación de la Encíclica Rerum Novarum en 1891 marcó un hito en este proceso, caracterizando el inicio de una nueva etapa de conciencia ante la cuestión social al situar el trabajo entre las preocupaciones privilegiadas de la Iglesia (11).

Desde la perspectiva de la inclusión en la sociedad civil y política, hubo quienes se adelantaron a la Encíclica. Augusto Orrego Luco fue de los primeros en referirse explícitamente a la "cuestión social" en una serie de artículos publicados en La Patria de Valparaíso en 1884 (12). Sostuvo que “... estamos envueltos en una cuestión social amenazadora y peligrosa, que reclama la más seria atención del estadista". Aunque Orrego Luco alerta contra el desarrollo del proletariado y teme la incertidumbre a que podría conducir al país, también aboga por la inclusión de los inmigrantes en el mercado de trabajo, en forma estable, a fin de hacerles "... entrar en las clases sociales" (13) y presentarles lo que llama "un núcleo de condensación", que no es otra cosa sino un sentido de pertenencia a la nación, que surgiría de un "trabajo organizado". Ese proceso de inclusión sería un requisito para que la educación rinda sus frutos y la moralidad se implante entre los sectores populares.

La Rerum Novarum dio un fuerte apoyo a quienes como Orrego Luco estaban repensando el rol de los católicos frente a los "otros", hasta ese momento asistidos solamente por la beneficencia. Aunque hay discrepancias sobre su recepción en Chile, lo cual se explica también por los sucesos de la Guerra Civil del 91 que acaparó la atención nacional, no hay duda que los sectores eclesiásticos y quienes lideraban intelectualmente el Partido Conservador combinaron la influencia del documento pontificio con el temor al descontento social y a la irreligiosidad del socialismo, para tomar conciencia que la cuestión social ponía seriamente en jaque su hegemonía social y política. El arzobispo Mariano Casanova fue muy cuestionado por su negativa a inmiscuirse en conjunto con los laicos en problemas vinculados al trabajo, e incluso acusado de tibieza en su respuesta a la Encíclica. Abdón Cifuentes criticó su falta de apoyo hacia el asociacionismo que él promovía para organizar redes de católicos comprometidos con la cuestión social. Cifuentes llegó a considerar que los laicos defendían mejor el catolicismo que los clérigos.

El proceso de reformulación del discurso del Partido Conservador es probablemente la más notable expresión de las dificultades que traía consigo la cuestión social para ese sector. En primer lugar, desde temprano habían liderado las actividades de caridad, muchas de ellas de la mano de sus mujeres, compenetrándose por lo tanto de la dramática situación de la pobreza urbana. Aunque sus portavoces habían sido los primeros en defender el sufragio universal, ello no puede confundirse con una voluntad de ampliación de la ciudadanía por razones doctrinarias. Esta postura se relacionó con una estrategia partidaria de consolidación de su apoyo electoral por

(10) Es la que en el siglo XX será la derecha. S. Correa, Con las riendas del poder: La derecha chilena en el siglo XX, Editorial Sudamericana, Santiago 2004.

(11) Cuarenta años después, Quadragessimo Anno impulsaría nuevos rumbos que corresponde analizar en el contexto de las divisiones de la década del 30 .

(12) A. Orrego Luco, “La Cuestión Social”, Imprenta Barcelona, Santiago 1884, en www.memoriachilena.cl

(13) El subrayado es mío. 
su incidencia sobre el voto campesino (14). Sin embargo, anticipa el reconocimiento explícito de que su hegemonía social depende de la preservación del control sobre el aparato político del Estado.

El Partido Conservador celebró convenciones en 1878, 1885 y 1891. Solo en la cuarta, de 1895, incorporó el tema de la cuestión social. Carlos Concha Subercaseaux propuso políticas concretas en el terreno de la educación, de vivienda popular y de amparo y trabajo para la mujer, todo ello inserto en los principios de la caridad. Pero específicamente afirmó que "el gobierno debe resguardar derechos y deberes de todos" (15). También Arturo Solar Vicuña, delegado por La Serena, insistió en el carácter democrático del partido, el cual se apoyaría en "principios de libertad que consultan realmente el bienestar del pueblo, fundando el bien común en la necesaria equitativa distribución de las tareas sociales, según los grados de cultura, adelanto y virtud de los ciudadanos" (16). Sin embargo, también mantuvo sus posturas reactivas y acordó "Intensificar la propaganda de la prensa cristiana para contrarrestar con ella las doctrinas del sectarismo antirreligioso y anárquico que es el carácter de la época presente" (17). Sin embargo, comenzó a surgir una postura donde el pobre es sujeto de caridad cristiana pero también detentor de ciertos derechos. En la Convención de 1901, el Partido Conservador definitivamente optó por legitimar una "vía política" para la solución de los problemas sociales. En ella defendió el rol político de los católicos y definió su suprema aspiración como "el mantenimiento y desarrollo del orden social cristiano", asignando a los laicos el desafío de incluir en pie de igualdad a sus connacionales, según su interpretación del mensaje del Evangelio. Sin embargo, como señala Gonzalo Vial, la definición de ese "orden" por su presidente Carlos Walker fue suficientemente amplia como para que no pueda ser considerada un antecedente demasiado relevante. Ella incluía: "Libertad de todos, amor entre los de abajo y los de arriba; ni opresores ni oprimidos, culto por todo lo noble y lo santo; honradez y trabajo; virtud y aliento fraternidad sincera". Su consecuencia era una petición de "generosidad al poderoso" y "resignación al pobre con el consuelo de otra vida mejor" (18). Las contradicciones y confusiones sobre qué hacer con los pobres son una demostración de que al interior del Partido se debatía la visión tradicional que privilegiaba la caridad con los nuevos requerimientos de justicia que algunos de sus miembros intuían. Baste recordar que incluso después de la huelga de 1903 y sus sangrientos resultados, el diputado Eulogio Díaz sostuvo en la Cámara que la cuestión obrera: “...en realidad, no existe en Chile” (19).

En una decisiva Primera Convención de la Juventud Conservadora en 1913, aparece una nueva generación que abiertamente se refiere a la "democracia cristiana". Alfredo Barros Errazuriz, presidente de la misma, recomendó no tener miedo "a

(14) Cfr. J. S. Valenzuela, op. cit.

(15) C. Concha Subercaseaux, La Convención Conservadora de 1895. Convocatoria-Discursos-Programa-Conclusiones, Imprenta y Encuadernación Roma, Santiago 1895.

(16) Solar Vicuña en ibid.

(17) Ibid.

(18) G. Vial, op. cit., 544.

(19) Hay que reconocer, no obstante, que similar ceguera mostraron en ese debate el radical Fidel Muñoz y el liberal Ramón Barros Luco. Mac Iver dijo que la cuestión social podía sintentizarse "en el salario mínimo". Ibid, 538. 
los avances populares, siempre que ellos se encaucen dentro de los límites de la verdadera democracia cristiana que es la salvación del porvenir". Esta nueva acepción del concepto de democracia incluye ya de lleno la inclusión del trabajo como un tema republicano. En ella se exigió para “...el progreso de la nación que se mejoren las condiciones del trabajo, hoy día entregadas casi completamente a la honradez y a la ambición personales de los patrones...". Estas mejoras debían incluir una legislación: de seguro obrero, de accidentes del trabajo, protección eficaz del salario, preocupación por los problemas morales asociados al inquilinaje, regulación del trabajo infantil y femenino (20).

En el progreso de esta nueva línea fue decisivo el discurso de Rafael Luis Gumucio, a la Convención Provincial del Partido de Valparaíso. En 1913, este afirmó: "Es preciso que marchemos junto con el pueblo, que sirvamos sus intereses, tomando la ofensiva contra los que... ahondan la crisis económica y encarecen la vida popular" (21). Hacia 1918, esta línea parecía haberse impuesto. En la Convención de ese año, el Informe de la Comisión de Estatutos y Programa recomendó importantes medidas de acción social para adecuarse al "criterio del derecho social contemporáneo" y a las "enseñanzas de la Iglesia... teniendo en consideración que el Partido forma una verdadera democracia respetuosa de los derechos y dignidad humana...". Entre ellas se incluyó dar patria potestad a las madres y mejorar la condición legal de la mujer, proteger a la infancia, construir habitaciones para obreros, reconocimiento de los sindicatos, fijación de horas de trabajo, etc. Incluso, la Convención recomendó “... sea designado para el próximo periodo legislativo, un representante de los obreros como candidato a diputado por Santiago" (22). En el terreno de las prácticas políticas, efectivamente miembros del Partido Conservador propusieron y obtuvieron importantes reformas que afectaban los derechos civiles de los sectores populares, entre ellas la Ley de Habitaciones Obreras de 1906, y la Ley de Descanso Dominical de 1907. Estas se sumaron al patrocinio anterior de asociaciones de obreros, en las que participaron activamente Abdón Cifuentes y Ramón Angel Jara, para la "moralización, instrucción y unión de los obreros católicos" (23).

Mientras el Partido Conservador evolucionó intentando arrebatar trincheras al socialismo y mantener su hegemonía social y política por la vía de una inclusión controlada de los temas vinculados al trabajo en la discusión republicana, la jerarquía de la Iglesia se parapetó en su crítica al liberalismo y al socialismo, en su defensa de un Estado confesional, y en su apoyo a un asociacionismo protegido. Entre 1880 y 1920 su prensa debatió largamente los temas vinculados a la cuestión social. Alarmada, la Revista Católica publicaba que "el edificio social bambolea”, y “... principia a faltar ya el centro de gravedad" (24). La actitud de los representantes eclesiales y el

(20) A. Barros Errázuriz, Primera Convención de la Juventud Conservadora celebrada en Santiago, del 1 al 5 de enero de 1913, Imprenta La Ilustración, Santiago 1914.

(21) R. L. Gumucio, Rumbos del Partido Conservador. Discurso en la Convención Provincial de Valparaíso, Litrografía e Imprenta Moderna, Santiago 1913.

(22) "Informe de la Comisión de Estatutos y Programa sobre los Proyectos de Reformas al Programa, presentados a la Convención", en Convención Conservadora convocada para los días 29 de septiembre de 1918 y siguientes en Santiago de Chile, Imprenta Cervantes, Santiago 1918.

(23) A. Cifuentes, Memorias, tomo II, Editorial Nascimento, Santiago 1936, 149.

(24) “Estudios Sociales", La Revista Católica, año 3, № 66, 16 de abril de 1904. 
texto de sus escritos son de alarma. La Iglesia quiere recuperar terreno, volver hacia un lugar de armonía alterado, reaccionar contra los nuevos tiempos más que leer el signo de los mismos. En ese dilema, Casanova remó en aguas turbulentas, elaborando respuestas ad hoc a las premuras de los desafíos, sin claudicar ante liberales ni clericales, ganándose por lo tanto enemigos entre ambos (25).

La primera reacción oficial de la Iglesia respecto de la cuestión social fue la Pastoral de monseñor Mariano Casanova, con motivo de la publicación de la Rerum Novarum. En ella recomendó seguir las instrucciones papales insistiendo especialmente en la necesidad de reaccionar ante el mal que acechaba. De hecho, su primer comentario fue que la Encíclica “...señala al socialismo como un peligro formidable que amenaza destruir el fundamento mismo de la sociedad humana, estableciendo una igualdad de condiciones y de fortunas contrarias a su naturaleza y a las disposiciones de la Providencia". Frente a la "llaga mortal" que este causa, y a las huelgas que "como gérmenes malsanos" comienzan a producirse, Casanova recomienda una lectura de la Encíclica que privilegie la fundación de mutuales y patronatos que por medio de la caridad sean "puertos de salvación" para el pueblo que trabaja (26). Los particulares son llamados a tomar la iniciativa siendo el rol del Estado apenas el de no "estorbar" el trabajo individual de los católicos.

En 1893, Casanova difundió una importante Pastoral sobre la Propaganda de Doctrinas Irreligiosas y Antisociales. En ella, condenando nuevamente al socialismo, insistió en que solamente la religión es "garantía del respeto y obediencia debidos a los depositarios del poder público. Dando a la autoridad un origen divino, la reviste a los ojos de los pueblos de un carácter augusto y sagrado, que le procura mayor ascendiente sobre los súbditos". Su hija es la caridad, que cura y remedia “... la mitad al menos de los males de la vida humana", y ella está en manos del sacerdocio. El socialismo y comunismo, en cambio, con su consigna contra los ricos pretenden destruir “... la desigualdad de condiciones sociales en que se funda la sociedad". "Y de esta desigualdad resulta la armonía social, esa variedad en la unidad que es como el sello de las obras divinas" (27).

La Revista Católica ejerció como principal portavoz de la Iglesia (28). Su importancia quedó acrecentada cuando en 1892 varió su frecuencia de quincenal a semanal. Su tónica fue la crítica hacia quienes propiciaban, como escribió José Ramón Gutiérrez "una igualdad imposible" (29) y hacia las asociaciones dejadas a

(25) Sobre las relaciones entre la Iglesia y el Partido Conservador, ver J. S. Valenzuela y E. Maza, "The Politics of religión in a catholic country: Republican democracy, Cristianismo Social and the Conservative Party in Chile, 1850-1925", en A. Ivereigh (Ed.), The Politics of religión in an Age of Revival, Institute of Latin American Studies, Londres 2000.

(26) M. Casanova, Pastoral que el Ilmo. y Rmo. Señor D. Mariano Casanova, Arzobispo de Santiago de Chile, dirige al clero y fieles al publicar la Encíclica de Nuestro Santísimo Padre León XIII sobre la condición de los obreros, El Porvenir, Santiago, 24 de septiembre de 1891.

(27) M. Casanova, Pastoral que el Illmo. y Rmo. Sr. D. Mariano Casanova, Arzobispo de Santiago de Chile, dirige al clero y pueblo sobre la propaganda de doctrinas irreligiosas y antisociales, Imprenta de Emilio Pérez L., Santiago 1893.

(28) Durante estos años hubo una proliferación de prensa católica. Entre 1812 y 1827 hubo dos periódicos católicos; entre 1828 y 1851, cuatro nuevos; entre 1851 y 1865 , cinco; entre 1866 y 1891 hubo dieciocho nuevos periódicos. Incluidos los de dependencia eclesiástica y laicos.

(29) J. R. Gutiérrez, La Revista Católica, 1334, 12 agosto 1893. 
la libre iniciativa popular. Especialmente se dedicó a predicar contra la irreligiosidad y sus consecuencias sociales: "Fuera de la religión, no hay una sola razón que valga para exigir al pueblo que acepte su sacrificio de todos los días y se mantenga en la resignación", apareció en un artículo de 1893. Por lo tanto, se propone reforzar la fe que "... ha mantenido a las clases inferiores resignadas con su suerte en las sociedades cristianas" (30). El Chileno y El Mensajero del Pueblo y El Estandarte Católico reforzaron el aparato comunicacional de la Iglesia. Por ejemplo, en 1893, el primero insistía en que la solución a los problemas podía "...reunirse en una palabra y una idea que son también la síntesis de nuestra religión: caridad”. Y agregaba: "Ella es el solo remedio; la única salvación de las sociedades actuales minadas por una incredulidad materialista... Solo ella puede fundir al mundo moderno con sus clases y sus intereses antagónicos, en un abrazo universal de fraternidad no mentida y de armonía estrecha y perdurable" (31).

Otra crítica emprendida por la Revista fue hacia sus ex aliados conservadores y la posible reformulación del concepto de democracia al interior de este Partido: "Mienten los conservadores exagerados, porque la democracia cristiana está en abierta oposición al socialismo... porque desde su fundación la Iglesia ha sido siempre democrática y a ella debe el pueblo todo lo que ha conseguido durante diecinueve siglos". Su interpretación de la Rerum Novarum es que, en su permanente defensa de las clases "bajas", hoy la Iglesia "se vale del pueblo para obtener el bien del pueblo, pero no lo arma contra los poderosos..." El pueblo debe ejercer su sufragio para defensa de sus intereses; jamás “...comenzar a levantarse por sí mismo...". Es la Iglesia la encargada de conducir sus pasos a fin de "comenzar de nuevo" la labor destructora del "liberalismo". Debe apropiarse de la democracia, ese movimiento que es "irresistible" en la época moderna. Si se hace con la Iglesia, “... sin dejar de ser democrático, será cristiano; sin nosotros, será forzosamente ateo". El Estado no puede ser agente de cambio democrático, salvo a través de la legislación. El cambio real requiere de la virtud, de la prudencia y de un desprendimiento imposibles en el Estado democrático. "Querer realizar estas hipótesis en una sociedad fundada sobre la igualdad de derechos y condiciones, es perseguir una utopía". Apelando nuevamente a la Encíclica de León XIII, la proposición final es que la religión “... es la única que puede arrancar de raíz el mal...", razón por la cual todos deben poner la mira principalmente en la recuperación de las costumbres cristianas. "El Estado debe facilitar a la Iglesia su acción regeneradora, procurando que llegue hasta los últimos gremios y clases de la sociedad y todo lo informe con el espíritu cristiano" (32).

El arzobispo Casanova dedicó especial atención a definir precisamente el sentido de la "acción popular cristiana", según la Ordenanza Fundamental dictada por Pío X, diferenciando la llamada "democracia cristiana" de la "democracia social". La primera debe basarse en la fe y moral católica, "no atentar en manera alguna al derecho inviolable de la propiedad privada", y "jamás mezclarse con la política ni...

(30) S. Grez, op. cit., 417.

(31) El Chileno, Santiago, 8 de agosto de 1893.

(32) P. F. Iñiguez, Notas sobre el desarrollo del pensamiento social en Chile, Editorial Jurídica, Santiago 1968. 
servir a partidos (33). En el documento, Su Santidad reforzaba también la inconveniencia de que la democracia se mezcle con la política, o sirva a partidos y sus fines, “... porque ese no es su campo, sino que debe ser una acción benéfica a favor del pueblo...". De allí que los escritores cristianos deban someter sus textos a la censura.

El Primer Congreso Eucarístico de ese mismo año fue otra ocasión importante para plantear la postura eclesiástica ante la cuestión social. A la discusión anterior sobre el concepto de igualdad, se agregó el de libertad. Propuso restaurar su definición "hoy día también perturbada" por el liberalismo a su sentido cristiano. Entre los temas sociales incluidos en su agenda se debatió sobre los deberes de los patrones, sobre la educación social y sobre los círculos de obreros. Sobre estos últimos se acordó que "la dirección de los círculos corresponderá conjuntamente a obreros y personas de clase alta, entre las que no debe faltar un director eclesiástico". Rafael Edwards Salas disertó sobre las condiciones generales de la Acción Democrática Cristiana (34).

Monseñor Casanova escribió su última pastoral en 1905: “Acerca de la necesidad de mejorar la condición social del pueblo", demostrando su creciente dolor ante la cuestión social. Refiriéndose a la vivienda popular, decía que eran "tugurios", y concluyó exclamando: "Esto es horrible!" (35). A su muerte en 1908, le sucedió en la silla arzobispal Juan Ignacio González Eyzaguirre quien en 1910 justamente publicó una nueva Pastoral "Sobre la Cuestión Social". En ella, introdujo dos nuevos elementos a la discusión social. En primer lugar, junto con defender el carácter religioso de las asociaciones obreras, amplió el ámbito de responsabilidad de los católicos desde la caridad hacia la justicia. "La rectitud y la justicia llevan la paz y el bienestar a todas partes; son el principal elemento de orden, y, deben ser la regla invariable que informe el criterio de los gobernantes". En segundo lugar, reconoció al Estado un lugar preponderante en la defensa de la misma: "Es obra propia de un buen Gobierno, es acción correspondiente a un Congreso verdaderamente democrático, hacer que la política converja al terreno social y económico en que deben resolverse los problemas que interesan a las clases trabajadoras". Es decir, asigna una legitimidad independiente de la religión a las reivindicaciones sociales y a sus actores y representantes (36).

La iniciativa más importante fue la convocatoria a un Congreso Social Católico, al cual se invitó “... a los católicos de todo el país”, sin distinciones. Con el título común de Acción Social, la Revista Católica publicó una serie de artículos a propósito del Congreso, donde destaca, por una parte la intención de ampliar también geográficamente el ámbito de su intervención social, desde el centro hacia las provincias. Sin embargo, y especialmente relevante era la evolución del concepto de

(33) La Revista Católica, 62 (1904), 66. “Actos y Decretos de la Santa Sede. Motu proprio de su Santidad Pío X sobre la Acción Popular Cristiana”, Roma, 18 de diciembre de 1903.

(34) Cfr. P. F. Iñiguez, op. cit.

(35) M. Casanova, Pastoral acerca de la necesidad de mejorar la condición del pueblo, en Boletín Eclesiástico 16, 406-410, Santiago 1905.

(36) J. I. González Eyzaguirre, "Pastoral sobre la Cuestión Social", en Actos y Decretos del Arzobispado, La Revista Católica, año 9, n. 211, 7 de mayo de 1910. 
democracia. “...La democracia bien entendida no consiste en otra cosa que en la cooperación de los esfuerzos de todos para el bien común, y principalmente para el bien de aquellos que más lo necesitan: las clases populares". Aquí sí, los católicos, preocupados por la cuestión social son definitivamente incorporados a una misión cívica de ampliación del contenido nacional: "Al preocuparse pues los católicos de las obras sociales, no hacen más que demostrar una vez más que los principios del Evangelio no forman solo buenos cristianos, sino también ciudadanos patriotas y abnegados; que manifiestan no solo con palabras, sino lo que más vale, con hechos prácticos, que desean con verdadero amor el bienestar y engrandecimiento de la Patria" (37).

Entre 1910 y 1920 el discurso democrático de justicia social y de reconocimiento de derechos de los trabajadores continuó permeando a los sectores católicos. Será en esa la década cuando se profundizará el clamor, incluso dentro de sectores del clero, por la intervención estatal a favor de las clases populares. Las figuras de Rafael Edwards Salas y Guillermo Viviani, entre otros religiosos, anticiparán la vinculación estrecha y creciente entre religión y justicia social. La caridad, apoyada como iniciativa privada, cederá ante la presión por la defensa de los derechos de los trabajadores como preocupación privilegiada de los católicos sociales. Consecuente con ello, en 1919, Viviani escribió en la Revista Católica, en la sección Sociología un artículo titulado "La Democracia", donde afirma que esta "... también se caracteriza por la intervención del Estado en las relaciones entre el capital y el trabajo. Es necesaria la ley. El fin del Estado es promover la prosperidad temporal pública de la nación. Sus leyes por consiguiente, deben no tan solo dejar hacer o dejar pasar sino ayudar a hacer". La crítica al liberalismo había transitado desde su irreligiosidad a su falta de solidaridad social. Cuando en 1920, Rafael Edwards escribió en "Sobre la Cuestión Social" (38) que "la participación de los obreros en la utilidad de los negocios no está fundada en la justicia conmutativa, sino en la justicia social" y propuso la participación de los obreros en las utilidades de las empresas no hizo sino confirmar que lentamente se había impuesto un nuevo discurso para una nueva época La reticencia a entender los signos de los tiempos por parte de los sectores reacios a la ampliación de la cobertura social de la nación configuró un sector que durante el siglo XX tendería a enclaustrarse en detrimento de la catolicidad del país. El catolicismo social en cambio iniciaría un largo peregrinar hacia la adecuación del mensaje evangélico y su opción por los excluidos con sus doctrinas y prácticas políticas.

\section{CONCLUSIÓN}

El sistema republicano por el cual Chile optó en la Independencia había sido definido como un tránsito desde una ciudadanía social y política restringida hacia la plena participación o actualización de los principios de soberanía popular. En ese

(37) Ibid.

(38) La Revista Católica, año 20, № 442, 3 de enero de 1920. 
contexto, las concesiones de derechos políticos no necesariamente debían corresponder a su equivalente en inclusión a la sociedad civil. La virtud, como ya lo había proclamado Portales, debía adquirirse en el tiempo y la democracia sería su consecuencia.

El surgimiento de la cuestión social hizo evidente este desequilibrio entre las definiciones republicanas y las prácticas políticas de las clases dirigentes, obligando a todos los sectores políticos a pronunciarse. Los católicos, naturalmente, debían ser especialmente convocados, no solamente por su obligación hacia los desposeídos sino porque las demandas de los sectores proletarios se escapaban de la tuición eclesiástica, surgían desde visiones laicas del mundo y, más aún se inspiraban en ideologías donde el catolicismo no tenía lugar. La virtual separación entre el ámbito religioso y el civil que impusieron las llamadas "leyes laicas" obligaba a usar nuevas estrategias de influencia sobre la feligresía, cada vez menos dependiente de la aprobación eclesiástica para el desarrollo de su vida civil.

Que el sector dirigente que había consolidado el Estado y pensado la nación como su prolongación se planteara adecuar el Estado a las necesidades sociales auguraba sin duda una inversión en los protagonistas privilegiados de la república. El pueblo soberano, la ciudadanía consagrada por la república como su actor fundamental se había impuesto asumiendo una realidad en que "unos" y "otros" tendrían que negociar en el futuro como integrantes iguales y libres de la nación.

Salvo las iniciativas aisladas de algunos estudiosos o parlamentarios, muchas de las cuales desembocaron en leyes favorables a los trabajadores, el primer catolicismo social tuvo dificultades para comprender que el pueblo había entrado para quedarse. Sin saber mucho "qué hacer con los pobres", tendió a enclaustrarse por los nuevos temores provocados por el ingreso a la opinión pública de los críticos del Centenario, "irreligiosos y anticatólicos furibundos", como les llama Gonzalo Vial. En ese contexto, puede sostenerse que la inspiración del Partido Conservador, en sus posturas de inclusividad política de los años 70 no estuvo en un comienzo encaminada hacia la creación de una ciudadanía moderna que ampliara los espacios de membresía nacional. A partir de la década del 90 se evidencia un cambio en la búsqueda de una adecuación doctrinario-religiosa respecto de su deber moral con "el otro" y la necesidad de responder creativamente ante el temor al avance del socialismo. En ese sentido se justifica la afirmación de la tibieza conservadora ante la Encíclica y la ceguera de algunos de sus representantes frente al problema obrero en sus dimensiones políticas y sociales.

En las proximidades del Centenario se evidenció que el descontento social era explosivo. Las primeras décadas del siglo XX encontraron a los conservadores intentando adaptarse y reaccionar ante la necesidad de otorgar derechos sociales. De hecho, sus iniciativas fueron talvez las más importantes que se plantearon en esos años.

La jerarquía eclesiástica, más atemorizada por el socialismo, el protestantismo, el liberalismo y por la irreligiosidad del siglo y probablemente más desconectada de los progresos en la autoconciencia popular fue aún más reticente a comprender que debía promover alianzas con el Estado, por duras que hubieran sido sus relaciones en los últimos años, y con sectores políticos, para no perder su influencia social y religiosa. En estos años no parece existir una sollicitudo rei socialis católica en 
estado puro, independiente de la contienda ideológica planteada por el socialismo. La política no debía ser rechazada como vía de acción para sus miembros, lo cual recién comenzó a imponerse en sectores del clero cuando el sistema oligárquico hacía agua.

La llegada a La Moneda de Arturo Alessandri en 1920 y los remezones de la década del 30 serían nueva inspiración para reformular, con nuevos actores, un pensamiento encaminado a la acción y a la inclusión teórica y práctica de los excluidos de la nación. Tanto desde el clero como desde los "emigrados" del Partido Conservador en la década el 30 surgieron voces que expresaron esta conciencia y lucharon por imponerla; son quienes comprendieron que la república transitaba irremediablemente de oligárquica a democrática. Nuevos actores defenderían la posibilidad de una democracia cristiana que también fuera democracia social. De salir adelante con sus postulados, la nación incluiría finalmente a todos sus habitantes con derechos políticos y sociales. Al menos ese era el sentido de su lucha.

\title{
RESUMEN
}

Este trabajo surge del interés por situar la discusión sobre el catolicismo social y la cuestión social en Chile en una nueva perspectiva historiográfica que relacione la historia social, la llamada nueva historia política y la historia de las ideas. Su intención es comprender esta discusión como parte del proceso de construcción nacional. Postula que la visibilización del proletariado y sus condiciones de trabajo, al provocar un cuestionamiento por parte de la clase dirigente y de los católicos que la integraban, indujo una reflexión sobre los integrantes de la nación chilena, es decir, sobre la soberanía nacional, en un contexto de democratización de la república.

Palabras clave: república, nación, cuestión social, catolicismo social, Iglesia/Estado.

\begin{abstract}
This work arises out of an interest in situating the discussion on Social Catholicism and the social question in Chile within a new historiographic perspective that puts social history, socalled new political history and the history of ideas into relationship with each other. The author's intention is to understand this discussion as part of the process of national construction. The author proposes that the act of making visible the proletariat and its working conditions, provoking questioning by the leadership class and of the Catholics that composed it, induced a reflection about membership in the Chilean nation-that is, about national sovereignty, within the context of the democratization of the republic.
\end{abstract}

Key words: Republic, Nation, Social Question, Social Catholicism, Church/State. 
